\title{
KONTRIBUSI PEMIKIRAN TAN MALAKA TENTANG KONSEP PENDIDIKAN KERAKYATAN DENGAN WAJAH PENDIDIKAN INDONESIA ERA MILENIAL
}

\author{
Kholfan Zubair Taqo Sidqi \\ Dosen FAI Unwahas Semarang \\ Email: akha.sidqi@gmail.com
}

\begin{abstract}
Abstrack: The concept of populist education promoted by Tan Malaka emphasizes local wisdom, equipping students with real skills to be useful for their nation. Moreover, capable education reach all levels of society, in line with the basic objectives of the Indonesian state. Education that designs schools as families, seems to be able to clarify the duties of a teacher as an educator. Protege too it is not only an academic problem, but its spiritual aspects can be developed in a balanced manner. Through populist education, able to humanize educators and students, all school members are able to work together to create the nation's ambition, as well as uplifting the dignity of the Indonesian nation. If the phenomenon of millennial era education is now out of what is being desired The aspirations of the founders of the Indonesian state, the concept of populist education is able to contribute as education that returns the noble ideals of the nation.
\end{abstract}

Keywords: Tan Malaka, populist education, and Indonesian education in the millennial era.

Abstrak: Konsep Pendidikan kerakyatan yang diusung oleh Tan Malaka dengan mengedepankan kearifan lokal, membekali anak didik dengan keterampilan nyata agar berguna bagi bangsanya. Apalagi Pendidikan yang mampu menjangkau segenap lapisan masyarakat, seiring dengan tujuan dasar negara Indonesia. Pendidikan yang mendesain sekolah sebagai keluarga, agaknya mampu memperjelas tugas seorang guru sebagai Pendidik. Anak didik juga dipacu tidak sekedar masalah akademik belaka, namun aspek rohaniah nya mampu dikembangkan secara seimbang. Melalui Pendidikan kerakyatan, mampu memanusiakan pendidik dan anak didik, segenap warga sekolah mampu bergotong royong demi mewujudkan ambisi bangsa, serta mengangkat harkat dan martabat bangsa Indonesia. Apabila fenomena Pendidikan era milenial kini keluar dari apa yang di cita-citakan para pendiri 
negara Indonesia, konsep Pendidikan kerakyatan mampu memberikan kontribusi sebagai Pendidikan yang mengembalikan marwah cita - cita luhur bangsa.

Kata kunci: Tan Malaka, sekolah kerakyatan, dan Pendidikan Indonesia era milenial.

\section{A. PENDAhuluan}

Pendidikan merupakan upaya yang dapat mempercepat pengembangan potensi manusia untuk mampu mengemban tugas yang d bebankan kepadanya. karena hanya manusia yang dapat dididik dan mendidik. Pendidikan dapat mempengaruhi perkembangan fisik mental emosional moral dan ketaqwaan manusia. ${ }^{1}$ Namun fakta nanti menunjukkan bahwa kemerdekaan fisik dan mental generasi muda Indonesia masih banyak diliputi ketimpangan. Mengapa? Karena fisik jasmaniah yang selalu menjadi prioritas utama (nilai mapel, peringkat kelas, serta prestasi akademik lain). Sementara kejujuran, tulus ikhlas, welas asih, gotong royong, ketaqwaan belum dimaksimalkan. Terbukti rentetan kekerasan dan kesenjangan masih saja terjadi. Hal yang sangat ideal manakala anak didik di pacu prestasi jasmani akademiknya, namun bersamaan pula dipupuk aspek batin rohaniahnya.

Ranah pendidikan yang notabene merupakan kawah cadradimuka masyarakat untuk mengetahui membaca dan mengenal keprbadian dan kemampuan diri serta sampai dimana kompetensi dirinya dalam hidup ini sebenarnya adalah ranah ideal dan signifikan.

1 Udin Saefudin \& Abin Syamsudin, Perencanaan Pendidikan, Remaja Rosdakarya, Bandung, 2005, hlm. 6 
Tapi masalah nya ada pada gerak dan proses ranah itu sendiri yang belum efektif dan efisien bagi kebutuhan dan keinginan masyarakat. Pendidikan yang ada hanya proses transfer pengetahuan saja dan belum menyentuh akar yang lebih mendasar lagi. Seperti penggalian kerpibadian potensi diri dan mental yang sanggup menghadapi derasnya perputaran roda zaman. ${ }^{2}$

Sejatinya Memanusiakan manusia merupakan hakikat pendidikan yang ada di Indonesia. Secara singkat bahwa memanusiakan manusia seutuhnya lahir dan bathin, jasmani rohani. Hal ini dilakukan agar sesama manusia supaya saling menghormati, membantu, bekerjasama. Tentunya berdasarkan sesama makhluk ciptaan Tuhan, sesama warga negara Indonesia. Hadirnya negara agar selalu terjamin dan terjaga hak hak warga negara, khususnya anak didik yang mengenyam pendidikan formal. Negara hadir guna menjamin secara menyeluruh terimplementasikannya Pancasila sebagai sendi pendidikan manusia Indonesia. Negara harus hadir dimanapun supaya saat menyelenggarakan pendidikan formal tidak ada ketakutan melanda anak didik, diskriminasi, kekerasan, mandulnya anak didik dalam inovasi dan nalar kritis. Apalagi pembunuhan karakter yang nyata - nyata akan membunuh karakter bangsa. Kekerasan, ketakutan, serta diskriminasi yang di alami anak didik tidak dibenarkan oleh perbuatan apapun.

Konsep pendidikan yang diusung oleh Sutan Ibrahim Gelar Datuk Sutan Malaka Jauh sebelum Republik Indonesia lahir dengan

${ }^{2}$ Sutrisno, Revolusi Pendidikan di Indonesia, Membedah Metode dan teknik pendidikan berbasis kompetensi, Ar Ruz, Yogyakarta, 2005, hlm. 5 
menggagas merdeka seratus persen. Sebagai lelaki yang di Juluki Muhammad Yamin sebagai "Bapak Republik Indoneisa" Tan Malaka memiliki visi jelas pendidikan di tanah airnya yaitu dengan menekankan bahwa pendidikan anak-anak tidak hanya sebatas kognitif, seperti mempelajari Sejarah, Ilmu bumi, dan Ilmu hitung yang sangat ditekankan di sekolah-sekolah Eropa pada masa itu. Tan Malaka memandang bahwa sebuah kewajiban untuk menanamkan etos kerja, dan keterampilan praktis yang akan menimbulkan rasa mencintai kerja kepada pribumi, dan seharusnyalah pendidikan memberikan nilai tambah. Jadi, usaha Tan Malaka ingin pendidikan semestinya mendahulukan kearifan lokal, agar masyarakat memperoleh bekal bagi penghidupannya. Oleh karena itu pendidikan kejuruan seperti: pertanian, perdagangan, teknik, dan administrasi harus dibenahi kualitasnya. Pendidikan praktis Tan Malaka diwujudkannya di sekolah Sarekat Islam. Sekolah SI berprinsip bahwa harus lebih sehat dan memiliki karakter keindonesiaan yang membedakan dengan sekolah Eropa. Konsep pendidikan Tan Malaka yang sangat sederhana tersebut merupakan hal luar biasa pada masa Tan Malaka merintis sekolah SI. ${ }^{3}$

Sepak terjang tentang Tan Malaka lewat pemikiran dan karya- karya tulisnya, yang meliputi semua bidang kemasyarakatan dan kenegaraan - politik, ekonomi, sosial, kebudayaan sampai kemiliteran (Gerpolek). Namun banyak orang tidak mengetahui, kalau Tan Malaka juga memiliki pemikiran tentang pendidikan, dan

${ }^{3}$ Salman Al Farisi, Pemikiran Politik Ekonomi Tan Malaka (Studi Pustaka Gerilya Politik Ekonomi Tan Malaka, Jurusan Filsafat Politik Islam, Fakultas Ushuludin IAIN Sunan Ampel 2012, hlm. 6

Progress - Volume 9, No. 2, Desember 2021 
ini tertuang dalam brosur SI Semarang dan Onderwijs. Sehingga Tan Malaka yang memprakarsai berdirinya Sekolah Sarekat Islam Semarang pada waktu itu, terlupakan oleh sejarah. ${ }^{4}$

Berikutnya melihat kondisi wajah pendidikan di Indonesia era milenial kini, pendidikan yang berdasarkan Pancasila selaras dengan apa yang digaungkan oleh Tan Malaka Tan Malaka tokoh gerakan perjuangan kemerdekaan ikut meletakkan dasardasar pendidikan bagi bangsa Indonesia. Khususnya berbicara pendidikan kerakyatan yang bermartabat, etos kerja, sekolah berkarakter keindonesiaan sudahkah benar - benar terwujud ?

\section{B. PROFIL SINGKAT TAN MALAKA}

Nama aslinya adalah Sutan Ibrahim Gelar Datuk Sutan Malaka. lahir di Nagari Pandan Gadang, Suliki, di Minangkabau, Sumatera Barat, lahir pada tanggal 2 Juni1897 Mendapatkan gelar pahlawan nasional pada tahun 1963, Tan Malaka dibesarkan dalam situasi adat yang pekat dan religius. Diceritakan, sang ayah adalah termasuk orang yang sangat taat menjalankan tarikat. Konon dalam suatu waktu, ayah Tan Malaka yang "mabuk rohani” ketika mengambil air wudhu di kolam, didapati tenggelam dengan badan setengah didalam air dalam keadaan pingsan. Ketika siuman ayahnya menceritakan bahwa ia bertemu dengan Tan Malaka berada di Negara Belanda. Sedangkan ibunya yang bernama Sinah adalah seorang penganut Islam yang teguh. Apabila sakit, Ibunya membaca Surat Yasin berkali-kali dan ayat-

\footnotetext{
${ }^{4}$ Salman Al Farisi, hlm. 5
} 
ayat suci Al-Qur'an lainnya untuk menentang datangnya malaikat maut. $^{5}$ Maka menjadi menarik apabila garis politik Tan Malaka meskipun pribadinya diklaim sebagai gerakan kiri/komunis, namun dalam sejarahnya Tan Malaka seorang Islam dan tertarik pada Islam sebagai basis pembebasan sosial dan orang yang berjuang membela Islam. $^{6}$

Setelah empat belas tahun setelah kematiannya, tepatnya pada 28 Maret 1963 Presiden Soekarno mengangkat nama Tan Malaka sebagai pahlawan nasional Indonesia. Namun 3 tahun kemudian, setelah Soekarno turun dari jabatan presiden (1966) dan digantikan oleh era Orde Baru. Nama Tan Malaka kembali disembunyikan dari sejarah Indonesia, dan bahkan tidak pernah disebutkan dalam daftar nama-nama pahlawan nasional di sekolah seluruh penjuru Indonesia selama puluhan tahun bahkan mungkin sampai sekarang. Penyebabnya? Apalagi kalau bukan keterlibatan Tan Malaka yang sangat kental dengan gerakan kiri, sosialis, atau komunis yang menjadi musuh besar pada era pemerintahan Orde Baru. ${ }^{7}$

Jika diperinci dari kisah Tan Malaka, tidak ada catatan bahwa dia terlibat pemberontakan PKI Madiun 1948 yang gagal. Tidak ada pula pengakuan dari tokoh - tokoh PKI yang tertangkap mengungkapkan keterlibatan Tan Malaka. Bahkan ketika Muso pulang ke Indonesia pada 1948, program politiknya memiliki

\footnotetext{
${ }^{5}$ Tan Malaka, MADILOG ( Materialisme, Dialektika, Logika ), Jakarta:Pusat Data Indikator, 1999,cet.Ke-1, hlm.381

${ }^{6}$ Badruddin, Kisah Tan Malaka Dari Balik Penjara dan Pengasingan, Yogyakarta, Araska, 2014 ,cet.Ke-1, hlm. 41

${ }^{7}$ https://www.zenius.net/blog/7968/biografi-tan-malaka, diakses tanggal 10 Oktober 2020

Progress - Volume 9, No. 2, Desember 2021
} 
beberapa kesamaan dengan Tan Malaka. Namun ketika ditanya wartawan apakah mereka akan bekerja sama? Muso menjawab sinis. Bila punya kesempatan katanya, yang pertama dilakukannya adalah menggantung Tan Malaka ${ }^{8}$. Mungkin karena pendapat Tan Malaka pasca kekalahan Indonesia $d$ ancah perundingan Renville, menyebabkan para pemimpin yang ingin berdamai dengan pihak penjajah gerah dengan pernyataan Tan Malaka. Maka Stigma melawan negara juga dialamatkan kepada beliau. Adapun pernyataan Tan Malaka yang menyulut semangat juang rakyat kala itu dengan menyampaikan bahwa:
a. Tidak mengakui Perjanjian Linggarjati dan Renville.
b. Menghancurkan negara boneka bentukan Belanda.
c. Mengambil alih semua wilayah Indonesia yang masih dikuasai oleh Belanda.

d. Mengambil alih semua aset Belanda dan Eropa lainnya.

e. Mengembalikan harga diri rakyat Indonesia.

f. Mengabaikan seluruh ajakan perundingan.

g. Tidak menyetujui perjanjian apapun yang tidak menyebutkan bahwa Indonesia merdeka pada tanggal 17 Agustus 1945

h. Menyatukan seluruh partai dan badan keamanan rakyat.

Himbauan inilah yang membakar semangat rakyat tapi juga sekaligus menyebabkan Tan Malaka dianggap sebagai pemberontak yang dianggap berbahaya oleh pemerintahan Perdana Menteri Muhammad Hatta. Sejak saat itulah Tan Malaka diburu oleh tentara negara yang dia bela mati-matian selama 30 tahun terakhir, 
sampai akhirnya terbunuh oleh tentara nasional Indonesia di Kediri Jawa Timur pada tanggal 19 Februari 1949 dan jenazahnya tidak diketahui keberadaannya sampai sekarang. (ada yang menyebutkan Tan Malaka dikubur secara rahasia, ada versi lain yang menyebutkan mayatnya dihanyutkan di Kali Brantas). ${ }^{9}$

Selanjutnya dalam merintis pendidikan untuk rakyat Indonesia pada saat itu mayoritas orang miskin, tujuan utamanya adalah usaha besar dan berat untuk mencapai Indonesia Merdeka. Karena Tan Malaka berkeyakinan bahwa kemerdekaan rakyat. Sementara itu, bagi Tan Malaka pendidikan juga sebuah alat. Alat untuk berjuang melawan ketertindasan. Hal ini jelas dalam tujuan pendidikan kerakyatan Tan Malaka, bahwa pendidikan harus bisa menghadapi tantangan jaman, juga dapat mengembangkan fitrah yang dimilikinya dan memiliki kepribadian yang tangguh, kepercayaan pada diri sendiri, dan cinta kepada rakyat miskin. Juga harus selalu membantu kepada rakyat yang lemah dan membutuhkan. ${ }^{10}$ Jadi, usaha Tan Malaka secara aktif ikut merintis pendidikan adalah menyatu dan tidak terpisah dari usaha besar memperjuangkan kemerdekaan sejati bangsa dan rakyat Indonesia. Tan Malaka berkeyakinan bahwa kekuatan pendorong pergerakan Indonesia terletak pada seluruh lapisan dan golongan rakyat melarat Indonesia,

\footnotetext{
${ }^{9}$ https://www.zenius.net/blog/7968/biografi-tan-malaka, diakses tanggal 27 Oktober 2020

10 Achmadi, Idiologi Pendidikan Islam; (Paradigma Humanisme Teosentris,) Yogyakarta: Pustaka Pelajar, 2005, hlm. 21 
tidak peduli apakah ia seorang Islam, seorang nasionalis ataupun seorang sosialis. ${ }^{11}$

\section{PENDIDIKAN KERAKYATAN DENGAN KONSEP} MEMANUSIAKAN MANUSIA

Menurut perspektif humanisme religius guru tidak dibenarkan memandang anak didik dengan mata sebelah, tidak sepenuh hati atau bahkan memandang rendah kemampuan siswa. Karena alasan - alasan kultural biasanya guru di negara berkembang termasuk di Indonesia sering terjerat dalam pandangan yang salah ini. Sejarah kolonialisme berperan buruk dalam membentuk sikap guru yang sok berkuasa dan menindas siswa. Jika dulu bangsa ini di jajah, sekarang saatnya guru menjajah. Dengan kata lain feodalisme kolonial tetap berpengaruh d sini. Sebagai akibat dari padangan yang bertentangan dengan humanisme religius siswa tidak mampu menembangkan diri dan tidak mengalami interaksi yang positif dengan guru. Oleh karena itu lahirlah individu - individu yang tidak percaya diri, inferior, dan pada gilirannya tidak memberi respek pada guru. ${ }^{12}$

Memanusiakan manusia dapat melalui muatan Pendidikan humanistik sebagai sebuah proses pendekatan. Pengembangan potensi peserta didik sebagai manusia seutuhnya diharapkan secara optimal menjadi pendekatan dalam pendidikan. Muaranya, anak didik mampu menemukan jatidirinya sebagai manusia, serta mampu belajar menerima keunikan orang lain sebagai sesama

${ }^{11}$ Salman Al Farisi, hlm. 7

12 Abdurrahman Mas'ud, Menggagas Format Pendidikan Non dikotomik, Gamamedia, Yogyakarta, 2002, hlm. 195 
manusia. Jika ditemukan hal yang berbeda, maka dianggap lumrah. Carilah kesamaan benang merahnya dalam menggapai tujuan. Bukan sebaliknya, anak didik asing dengan jatidirinya sebagai manusia yang merdeka, bahkan menjadi lebih asing dengan sesamanya, karena minimnya waktu dan kesempatan yang dimiliki disekolah dalam mengenal seluk beluk sesamanya. Janganlah anak didik sebagai obyek belaka tuntutan dari sekolah hanya capaian akademik semata.

\section{PENDIDIKAN KERAKYATAAN MENGUSUNG GOTONG ROYONG}

Ciri khas yang ada di Indonesia dan sangat kental dengan kebersamaan adalah kerja gotong royong. Rawe- rawe rantas malang malang putung. Harus ada kolektivitas yang terkandung di dalamnya. Kebersamaan itu terbukti dengan gotong royong. Hal ini seperti yang telah disampaikan oleh M. Bambang Pranowo, dalam Multidimensi ketahanan Nasional. Disebutkan bahwa untuk bisa bertahan dan berkembang, setiap bangsa termasuk bangsa Indonesia harus mengenal dan memahami jati dirinya. Lalu apa jati diri bangsa Indonesia? Bung Karno menyatakan bahwa jati diri bangsa Indonesia adalah gotong royong. Jika semua sila dalam Pancasila diperas, menurut Bung Karno, maka hasilnya adalah gotong royong. Pakar filsafat dari Universitas Indonesia M. Nasroen menyatakan bahwa gotong royong merupakan salah satu filosofi terpenting bagi bangsa Indonesia. Sehingga dengan filosofi itu Indonesia bisa bertahan dimasa lalu, masa kini dan masa yang akan datang. Dikaitkan dengan ketahanan nasional dapat dikatakan bahwa 
kekokohan ketahanan nasional sangat tergantung pada sejauh mana masyarakat Indonesia menerapkan prinsip dan semangat gotong royong dalam kehidupan nyata. $^{13}$ Sejarah mencatat kemerdekaan yang diraih bangsa Indonesia dicapai dengan kerja keras dan gotong royong seluruh rakyat.

Perlu diperjelas bahwa gotong royong memaknai kebersamaan dalam menyelesaikan permasalahan secara santun dan beradab. Tetapi gotong royong di Indonesia tidak mengenal sama rata sama rasa. Bila sama rata dan sama rasa diberlakukan, maka akan muncul ketidakadilan. Gotong royong dengan konsep keadilan, kesejahteraan, dan kemanuasiaan merupakan indentitas bangsa Indonesia.

Seandainya gotong royong yang menjadi slogan bangsa Indonesia sudah lazim dikenalkan di sekolah, maka kesenjangan serta rasa superior maupun rasa inferior akan dapat diminimalisir. Kepala sekolah, Guru, anak didik mampu sejajar dan bahu membahu merealisasikan Indonesia yang adil, makmur dan beradab. Bilamana hal ini telah diawali dari lembaga pendidikan formal.

\section{E. PENDIDIKAN YANG MERDEKA DAN BERMARTABAT}

Merdeka secara akal, serta bermartabat secara manusia. Karena martabat yang melekat pada diri anak didik adalah jatidirinya sebagai manusia seutuhnya. Bukan karena materi yang melekat pada dirinya. Jangan bayangkan kita memiliki partai seperti Sarekat Islam yang mendirikan sekolah dengan guru yang bernama Tan Malaka. Sekolah

${ }^{3}$ M. Bambang Pranowo, Multidimensi Ketahanan Nasional, Alfabet, Jakarta, 2010, 
itu dalam menarik biaya dilakukan murid sendiri dengan menjangkau selumlah orang kaya yang mempunyai pikiran masuk akal. Sekolah ini tanpa tukang kebun. Karena menurut Tan Malaka anak harus merasakan nikmatnya pekerjaan fisik. Sekolah Tan Malaka ini memang berbahaya karenannya pemerintahan kolonial segera melakukan pembredelan. Sekolah yang didirikan Tan Malaka ini menjadi cerminan kita bagaimana tanggung jawab kaum aktivis gerakan terhadap pendidikan rakyatnya. Alangkah tercelanya kita yang tidak mau belajar tentang sejarah. ${ }^{14}$

\section{F. REFLEKSI WAJAH PENDIDIKAN INDONESIA ERA MILENIAL}

Membahas fenomena pendidikan di Indonesia mestinya negara ini punya konsep tersendiri yang benarbenar sesuai dengan falsafah bangsa Indonesia, dan hal itu yang mulai merosot karena pendidikan hanya menekankan aspek jasmaniah belaka, sementara aspek rohaniah dan karakter belum tergarap secara maksimal. Biaya Pendidikan yang mahal serta penyimpangan lain sehingga pendidikan semakin jauh dari nilai-nilai budaya bangsa Indonesia. Meskipun serangkaian kurikulum telah di terapkan akan tetapi karater bangsa Indonesia, khususnya generasi mudanya dari hari kehari justru semakin menurun.

Walaupun dasar hukum konstitusional menyatakan kalau negara mengeluarkan anggaran $20 \%$ untuk biaya pendidikan, akan

14 Eko Prasetyo, Orang miskin dilarang Sekolah, Yogyakarta, Resist Book, 2004, 
tetapi di sisi lain ada desakan untuk pelaksanaan otonomi dan pengurangan subsidi. Kebijakan yang saling bertolak belakang ini ujung ujungnya membaawa korban masyarakat umum. Keluhan mengucur deras dari banyak anggota masyarakat mengenai biaya dan kualitas. Bicara kualitas, saya ingin menyitir pendapat seorang peneliti pendidikan.: menurut temuannya rata - rata setiap murid SD kelas 3 sampai kelas 6 dalam setiap kuartal mempelajari sejumlah buku yang bila ditimbang beratnya 43 kilogram! Luar biasa, sebab rata - rata berat seorang murid SD bahkan tak sampai angka itu. ${ }^{15}$

Tan Malaka memandang kemajuan untuk masa depan pendirian sekolah-sekolah harus didahulukan. Pendidikan adalah dasar untuk melepaskan bangsa dari keterbelakangan dan kebodohan serta belenggu Imperialisme-Kolonialisme. Tan Malaka menekankan pada materi pendidikan dan mengenai hal itu dapat disimpulkan menjadi tiga bagian yaitu:

1) Memberi senjata yang cukup buat mencari kehidupan dalam dunia kemodalan (berhitung, membaca, menulis, ilmu bumi, bahasa asing, bahasa Indonesia dan bahasa Daerah).

2) Memberi haknya terhadap murid-murid yakni harus dengan jalan pergaulan (Vereeniging).

3) Menujukkan kewajiban terhadap berjuta-juta kaum Kromo (rakyat jelata).

Ketiga tujuan diatas telah diterapkan pada sekolah

${ }^{15}$ Eko Prasetyo, Orang Miskin dilarang Sekolah, hlm. 13 
yang didirikan sebelumnya seperti di Semarang, Jawa, Suka Bumi dan Surabaya yang merupakan sekolah Syarikat Islam. Namun sangat disayangkan usaha ini tidak dapat diteruskan karena beberapa bulan setelah sekolah ini berkembang Tan Malaka harus meninggalkannya karena dihukum buang pemerintah kolonial Belanda. Dalam hal ini, Tan Malaka mengeritik kaum terpelajar Indonesia yang mendapatkan pendidikan Barat tapi tidak mau memperhatikan nasib Kaum Kromo (rakyat jelata) yang merupakan bagian dari diri mereka juga. Pemikiran Tan Malaka mengenai pendidikan dianggap sebagai modal dasar bagi kemajuan dari bangsa yang merdeka dalam politik, ekonomi, sosial dan budaya sehingga menjadi bangsa yang sejajar dengan bangsa-bangsa lain. ${ }^{16}$ Dari uraian peristiwa $d$ atas bahwa fenomena Pendidikan yang sekarang terjadi d Indonesia diantarannya;

\section{1) Kekerasan di dunia pendidikan datang silih berganti}

Jika masyarakat Indonesia mendengar tawuran pelajar, itu sudah menjadi pemberitaan yang biasa. Tetapi ada hal yang sangat disayangkan di dunia Pendidikan manakala seorang pendidik mengalami penderitaan akibat dianiaya anak didiknya. Miris sekali fakta tersebut. Ada kegersangan karakter yang dialami anak didik. Seperti yang diliput oleh CNN Indonesia;

\footnotetext{
${ }^{16}$ Hambali, Konsep Pendidikan dalam Perspektif Tan Malaka, Jurnal Intelektualita, Volume 3 No 1 Edisi Januari - Juni 2015, hlm. 101
} 
"Seorang siswa Madrasah Darussalam, Kecamatan Pontianak Timur, Pontianak, Kalimantan Barat, NF diduga menganiaya gurunya, Nuzul Kurniawati, Rabu (7/3). Pemukulan dilakukan karena NF tak terima ditegur saat menggunakan telepon genggam ketika pelajaran berlangsung. "Dari penjelasan para guru yang saya terima, peristiwa itu bermula ketika mata pelajaran Sejarah Kebudayaan Islam di kelas VIII atau tepatnya di kelas NF, "kata Kepala Madrasah Darussalam, Ahmad Bustomi di Pontianak, Kamis (8/3) seperti dilansir dari Antara. Saat pelajaran berlangsung, siswa tersebut malah main ponsel. Pengajarnya saat itu bukan ibu Nuzul Kurniawati. Guru yang mengajarnya lalu menegur NF agar menyimpan ponsel tersebut, namun tidak dihiraukan".

Guru tersebut akhirnya keluar kelas dan bertemu Nuzul yang langsung masuk kelas VIII guna menasihati dan mengambil HP yang dipegang NF. Kondisi kelas saat itu sepi karena siswa lain ikut keluar begitu guru mata pelajaran mereka keluar. Mungkin $N F$, pelaku, tidak terima sehingga sempat terjadi adu mulut, mungkin karena kesal kursi plastik tempat duduk dia, dipukulkan kepada ibu Nuzul," ujarnya. Bustomi menuturkan karena kejadian itu, Nuzul Kurniawati sempat dibawa ke rumah sakit terdekat, dirujuk ke RSUD Soedarso untuk menjalani scanner di bagian kepala. Hasil pemeriksaan menunjukkan tidak ada masalah, hanya saja di kerudung guru tersebut ada bercak darah. Pihak sekolah sudah melakukan mediasi, Bustomi berharap agar masalah itu bisa diselesaikan secara kekeluargaan, walau sudah dilaporkan kepada pihak kepolisian."Aturan sekolah memang tidak membolehkan siswa membawa handphone. Kami berharap dengan adanya kejadian ini, ada pelajaran yang bisa diambil, terutama memperketat aturan yang berlaku," katanya.

Wujud kekerasan ini justru malah menciderai hakekat pendidikan d Indonesia yang bertujuan memanusiakan manusia, ternyata disinilah manusia terampas kemerdekaan dan kenyamanannya sebagai warga negara. Generasi muda bangsa

${ }^{17}$ Wishnugroho Akbar, CNN Indonesia | Kamis, 08/03/2018 17:46 WIB, diakses tanggal 27 Oktober 2020

Progress - Volume 9, No. 2, Desember 2021 
Indonesia terperangkap dalam gulita anarkis terstruktur. Mengapa? Karena kekerasan \& kebrutalan justru datang dari lembaga pendidikan tempat mereka menuntut ilmu.

\section{2) Anak didik mengalami pengikisan moral}

Zakiah Daradjat (1978:67) mengatakan, moral bukanlah suatu pelajaran yang dapat dicapai dengan mempelajari saja, tanpa membiasakan hidup bermoral sejak kecil. Moral itu tumbuh dari tindakan kepada pengertian dan tidak sebaliknya. pada pengertian dan tidak sebaliknya. Seperti halnya rumah tangga, yang dijadikan sebagai basic-education, sekolah pun memiliki peranan penting dalam pembinaan moral anak didik. Hendaknya sekolah dapat dijadikan sebagai lapangan untuk menumbuhkembangkan mental dan moral anak didik, disamping ilmu pengetahuan, pengembangan bakat dan kecerdasan. Untuk menumbuhkan sikap moral yang demikian itu, pendidikan agama di sekolah harus dilakukan secara intensif agar ilmu dan amal dapat dirasakan anak didik di sekolah. Apabila pendidikan agama/moral diabaikan di sekolah, maka didikan agama/moral yang diterima di rumah tidak akan berjalan dengan baik, bahkan mungkin paradoks (berlawanan), dan berdampak pada kegagalan pendidikan moral. ${ }^{18}$ Peristiwa yang membuat miris dunia Pendidikan adalah adanya kejahatan aborsi secara sengaja.

"Kedua pelajar kelas 3 sebuah sekolah menengah kejuruan menggugurkan si jabang bayi saat sudah berumur lebih dari 7

${ }^{18}$ Mochamad Iskarim, Dekadensi Moral di Kalangan Pelajar (Revitalisasi Strategi PAI dalam Menumbuhkan Moralitas Generasi Bangsa), Edukasia Islamika : Volume 1, Nomor 1, Desember 2016, hlm. 6 
bulan. Pelajar itu NA (inisial), perempuan berumur 18 tahun, warga Desa Sukoreno. NA mengandung anak yang sudah berusia 7 bulan dari WL (inisial), laki-laki berumur 19 tahun, asal Desa Tuksono. Keduanya sepakat menggugurkan kandungan itu dengan cara mengonsumsi obat khusus yang dibeli bebas secara online. Setelah ditanya, mereka membenarkan telah melakukan aborsi lantas memakamkannya," kata Komisaris Polisi Kodrat, Kepala Polsek Sentolo, Selasa (5/3/2019). Kedua pelajar yang menginjak kelas 3 ini menceritakan sudah menjalin hubungan selama 2 tahun belakangan. Namun belum lama, keduanya malah terlibat hubungan badan hingga NA berbadan dua pada Agustus 2018. WL dan NA menyembunyikan kehamilan itu dari orang sekitar, baik keluarga maupun teman sekolah. NA memakai baju ukuran besar untuk menyembunyikan kehamilannya. Keduanya akhirnya merasa terjepit keadaan. Terlebih, WL dan NA akan menghadapi ujian nasional pada April 2019 mendatang. Keduanya juga merasa belum siap berumah tangga. ${ }^{19}$

Secara terperinci dari contoh rentetatan peristiwa di atas bahwa keluarga, guru, masyarakat berperan memberi pengaruh kepada generasi mudanya. Namun jika hal salah yang dilakukan anak didiknya, belum tentu muncul dari kesalahan guru dan sekolah. Mengapa? Karena sekolah tercetak sebagai lembaga yang mengedepankan dimensi formal saja. Aspek sekolah sebagai rumah kedua bagi anak didik memang belum terserap secara utuh. Guru sebagai pendidik sekali lagi terperangkap dengan kelelahan administrasi yang tak berkesudahan. Kehangatan Guru dan anak didik yang terhimpun dalam keluarga

\footnotetext{
${ }^{19}$ Dani Julius Zebua, Kompas.com - 05/03/2019, 14:43 WIB, diakses tanggal 28 Oktober 2020
} 
yang bernama sekolah agaknya peristiwa mahal yang sulit untuk dijumpai.

\section{3). Guru mengalami pergeseran profesi}

Mutu pendidikan amat ditentukan dari mutu gurunya. Mendiknas bapak abdul malik fajar menyatakan dengan tegas bahwa guru adalah yang utama (republika, 2003) belajar bisa dilakukan di mana saja tetapi guru tidak dapat digantikan oleh siapapun atau alat apapun juga. Untuk membangun pendidikan yang bermutu, yang paling penting bukan membangun gedung sekolah atau sarana dan prasarananya melainkan harus dengan upaya peningkatan proses pengajaran dan pembelajaran yang berkualitas. Yakni proses pembelajaran yang menyenangkan yang mengasyikkan dan mencerdaskan. Kesemuannya itu hanya dapat dilakukan oleh guru yang bermutu. Abdurrahman Mas'us $(2003 ; 194)$ menyebutkan tiga kompotensi dasar yang harus dimiliki guru yaitu:

1) Menguasai bahan materi atau bahan ajar

2) Antusiasme

3) Penuh kasih sayang (loving) dalam mengajar dan mendidik $^{20}$

Namun apalah daya, seorang guru meski profesi utama adalah seorang pendidik, ada rentetan tuntutan administrasi yang menjadi rutinitas tiada henti. Waktu untuk bercengkrama secara hangat dengan anak didiknya hambar terpasung guna

${ }^{20}$ Suparlan, Menjadi Guru Efektif, Yogyakarta, Hikayat Publising, 2005, hlm. 99 Progress - Volume 9, No. 2, Desember 2021 
perkara administrasi. Kemerdekaan waktu bagi guru agar mampu dekat secara emotional dengan anak didiknya sekali lagi direngut oleh urusan administrasi. Sedangkan anak didik waktunya terampas guna menyelesaikan tugas - tugas sekolah yang membuat hati dan aktivitasnya terbebani. Tugas Administrasi penting, anak didik mengerjakan tugas untuk menunjang kefahaman juga penting. Namun identas sebagai makhluk sosial yang merdeka dan beradab, jangan sampai waktunya terampas dan berlalu dengan sia - sia.

\section{4) Sekolah mahal masih menjadi kendala}

Awal merekrut anak didik, ada jurus yang dilakukan agar orangtua terpikat oleh sekolah. Kemudian anaknya agar masuk ke Lembaga Pendidikan tersebut. Beberapa cara mempromosikan sekolah dengan fasilitas terbaiknya. Deretan pengajar dan staf yang di klaim mumpuni dalam bidangnya. Foto-foto kegiatan yang relevan dengan promosi, namun skenario tadi memiliki konsekuensi yang ditanggung orangtua anak didik. Utamanya dengan tarif yang sekolah patok. Banyak masyarakat yang masih menilai bahwa pendidikan di Indonesia masih tergolong cukup mahal. Mulai dari sekolah dasar hingga bangku kuliah banyak keluhan mahalnya pendidikan di Indonesia. Jika ditemukan sekolah murah dan berkualitas, sebenarnya itu bagian upaya negara dalam mencerdaskan anak bangsa. Namun fenomena ini justru masih langka ditemui. 
Akhirnya muncul kalimat Pendidikan bermutu itu mahal. Kalimat ini sering muncul untuk menjustifikasi mahalnya biaya yang harus dikeluarkan masyarakat untuk mengenyam bangku pendidikan. Mahalnya biaya pendidikan dari Taman Kanak-Kanak (TK) hingga Perguruan Tinggi (PT) membuat masyarakat miskin tidak memiliki pilihan lain kecuali tidak bersekolah. Orang miskin tidak boleh sekolah. Untuk masuk TK dan SDN saja saat ini dibutuhkan biaya Rp 500.000,- sampai Rp 1.000.000. Bahkan ada yang memungut di atas Rp 1 juta. Masuk SLTP/SLTA bisa mencapai Rp 1 juta sampai Rp 5 juta. Apa penyebab mahalnya biaya pendidikan? Makin mahalnya biaya pendidikan sekarang ini tidak lepas dari kebijakan pemerintah yang menerapkan MBS (Manajemen Berbasis Sekolah).

MBS di Indonesia pada realitanya lebih dimaknai sebagai upaya untuk melakukan mobilisasi dana. Karena itu, Komite Sekolah/Dewan Pendidikan yang merupakan organ MBS selalu disyaratkan adanya unsur pengusaha. Asumsinya, pengusaha memiliki akses atas modal yang lebih luas. Hasilnya, setelah Komite Sekolah terbentuk, segala pungutan uang selalu berkedok, "sesuai keputusan Komite Sekolah". Namun, pada tingkat implementasinya, ia tidak transparan, karena yang dipilih menjadi pengurus dan anggota Komite Sekolah adalah orang-orang dekat dengan Kepala Sekolah. Akibatnya, Komite Sekolah hanya menjadi legitimator kebijakan Kepala Sekolah, dan MBS pun hanya menjadi legitimasi dari pelepasan 
tanggung jawab negara terhadap permasalahan pendidikan rakyatnya. $^{21}$

Biaya tersebut diatas tidak termasuk uang jajan, uang transport, pengerjaan tugas dari guru. Belum pula dihitung untuk bayar ekstrakurikuler yang harus mengeluarkan uang lagi. Apalagi tugas study tour. Sudah jelas akan ada pengeluaran biaya. Saat kelulusan, mengambil ijazah, wisuda purnasiswa, dipastikan ada pungutan. Apakah Sekolah sekarang dalam melepas kepergian anak didiknya, lebih mementingkan seremoni belaka daripada kehikmatan serta rasa syukur atas ilmu bermanfaat yang telah didapatkan.

\section{G. KESIMPULAN}

Pendidikan Kerakyatan yang diusung oleh Tan Malaka tidak mustahil akan menjadi solusi bagi penyelenggaraan Pendidikan di Indonesia pada era milenial. Beberapa alasan logis yang dapat diterima agar Pendidikan Kerakyatan mampu mencapai semua lini kehidupan bangsa Indonesia bahwa;

a. Pendidikan kerakyatan tidak bertentangan dengan Pancasila dan UUD 1945

b. Pendidikan kerakyatan bersendikan kearifan lokal, sehingga anak didik era milenial tetap akrab dengan budayanya, jangan sampai produk pendidikan era milenial terasing dengan budaya luhur bangsanya.

\footnotetext{
${ }^{21}$ http://wadzifah.blogspot.com/2012/12/mahalnya-pendidikan-di-indonesia.html.
} Diakses pada tanggal 28 Oktober 2020 
c. Pendidikan kerakyatan dapat menjangkau seluruh lapisan masyarakat Indonesia tidak peduli Islam, Sosialis maupun nasionalis. Termasuk pendidikan yang mampu menjangkau kehidupan bangsa Indonesia dari segala strata sosial dan ekonomi.

d. Melalui Pendidikan kerakyatan Guru dan anak didik dapat menjalani hubungan harmonis dalam keluarga bernama sekolah. Bukan sebaliknya guru asing dengan anak didik lantaran tugas administrasi tiada henti, sedang anak didik hanya fokus pada aspek akademik belaka.

e. Pendidikan kerakyatan tidak hanya menanamkan aspek kognitif saja, namun juga menanamkan etos kerja dan keterampilan praktis yang akan menimbulkan rasa mencintai kerja kepada pribumi (tanah air).

\section{DAFTAR PUSTAKA}

Abdurrahman Mas'ud, Menggagas Format Pendidikan Non dikotomik, Gamamedia, Yogyakarta, 2002

Achmadi, Idiologi Pendidikan Islam; (Paradigma Humanisme Teosentris) Yogyakarta: Pustaka Pelajar, 2005

Asvi Marwan Adam, Menguak Misteri Sejarah, Kompas, Jakarta, 2010

Badruddin, Kisah Tan Malaka Dari Balik Penjaradan

Pengasingan, Yogyakarta, Araska, 2014 ,cet.Ke-1.

Eko Prasetyo, Orang miskin dilarang Sekolah, Yogyakarta, Resist Book, 2004

Hambali, Konsep Pendidikan dalam Perspektif Tan Malaka, Jurnal Intelektualita, Vollume 3 No 1 Edisi Januari - Juni 2015

http://wadzifah.blogspot.com/2012/12/mahalnya-pendidikan-di-indonesia.html https://denpasar.kompas.com/komentar/2019/03/05/14435421/gugurkan-kandungan-usia-

7-bulan-sepasang-pelajar-smk-ditangkap 
https://www.cnnindonesia.com/nasional/20180308171331-12-281519/ditegur-saat-mainhp-di-kelas-murid-pukul-guru-dengan-kursi https://www.zenius.net/blog/7968/biografi-tan-malaka

M. Bambang Pranowo, Multidimensi Ketahanan Nasional, Alfabet, Jakarta, 2010

Mochamad Iskarim, Dekadensi Moral di Kalangan Pelajar (Revitalisasi Strategi PAI dalam Menumbuhkan Moralitas Generasi Bangsa), Edukasia Islamika : Volume 1, Nomor 1, Desember 2016

Salman Al Farisi, Pemikiran Politik Ekonomi Tan Malaka (Studi Pustaka Gerilya Politik Ekonomi Tan Malaka), Jurusan Filsafat Politik Islam, Fakultas Ushuludin IAIN Sunan Ampel 2012.

Suparlan, Menjadi Guru Efektif, Yogyakarta, Hikayat Publising, 2005.

Sutrisno, Revolusi Pendidikan di Indonesia, Membedah Metode dan teknik pendidikan berbasis kompetensi, Ar Ruz, Yogyakarta, 2005.

Tan Malaka, MADILOG (Materialisme, Dialektika, Logika), Jakarta, PusatData Indikator, 1999,cet.Ke-1

Udin Saefudin \& Abin Syamsudin, Perencanaan Pendidikan, Remaja Rosdakarya, Bandung, 2005. 